\title{
Comparing the Effectiveness of Intravenous Oxytocin Versus Rectal Misoprostol in the Management of Third- Stage of Labour After Second-Trimester Abortion
}

\author{
Noushin Mobaraki, Fariba Kahnamouei-Aghdam*, Firouz Amani, Sousan Mahami
}

\begin{abstract}
Objectives: To compare the efficacy of intravenous oxytocin versus rectal misoprostol in the management of the third stage of labor during pregnancy termination.

Materials and Methods: In this randomized clinical trial, 100 pregnant women in active phase of labor and similar gestational age who had the inclusion criteria were randomly assigned into two groups of 50 patients each, for oxytocin (group 1) and misoprostol (group 2). Forty units of intravenous oxytocin was used as the standard regimen in the intervention group and compared with 400 $\mu \mathrm{g}$ rectal misoprostol in the control group. Necessary outcomes were analyzed by statistical methods in SPP 20.

Results: The frequency of retained placenta in the misoprostol group with 4 patients (8\%) was less than the oxytocin group with 8 cases $(16 \%)$, but not statistically significant. Decreasing hemoglobin concentration in the misoprostol group $(0.54 \mathrm{mg} / \mathrm{dL}) \mathrm{was}$ significantly lower than oxytocin group $(0.8 \mathrm{mg} / \mathrm{dL} ; P=0.001)$.

Conclusion: Results showed that using misoprostol in the third stage of labor in second-trimester abortions could reach a better outcome, regarding lower risks of hemorrhage and frequency of retained products of conception as compared to oxytocin.

Keywords: Abortion, Induced, Misoprostol, Oxytocin, Rectal administration
\end{abstract}

\section{Introduction}

Various reasons can lead to abortion in the second trimester of pregnancy. Abortion in the second trimester of pregnancy causes significantly more complications like hemorrhage and placental retention as compared to the abortions occurring in gestational ages less than 8 weeks. In order to control and improve the third stage of labor, several medications derived from oxytocin, ergots, and prostaglandin groups can be used orally, vaginally, and rectally (1-5). Rectal, vaginal and oral misoprostol can be used for controlling hemorrhage in the third stage of delivery. Rectal administration of misoprostol has the advantage of having high level of absorption in the body and fewer complications in comparison to its oral form. Cases of retained placenta in different studies have been reported between $8 \%-80 \%(6,7)$. The aim of this study was to compare the efficacy of intravenous oxytocin versus rectal misoprostol in the management of the third stage of labor during pregnancy termination.

\section{Materials and Methods}

In this randomized clinical trial, 100 women with gestational age of 14-28 weeks, visiting for terminating the pregnancy due to intrauterine fetal death (IUFD) or approved premature rupture of membrane (PROM), entered the study. After being informed about the possible abortion procedures, medications, side effects and methods of implementation, they completed the consent form and were divided into two groups of 50 patients each by random selection methods (by selecting one of the red and blue cards). All women in the two groups (oxytocin and misoprostol) underwent the same protocol of receiving $200 \mu \mathrm{g}$ vaginal misoprostol every 6 hours. In case of having cesarean, lower doses of misoprostol were administered, which lasted for 24 hours, and if no response was received, it would be continued for the next 24 hours. After 48 hours, while considering the condition of the cervix and its dilation, other methods such as putting catheter into the cervix or using high doses of oxytocin would be used.

After recording the time of fetal expulsion, intravenous oxytocin including 40 units of oxytocin in a liter of normal saline during one hour was administered to one group and $400 \mu \mathrm{g}$ of rectal misoprostol was administered to the other group. We had 1 hour to register the time of placenta expulsion and during this time the patients were monitored every 15 minutes and their vital signs including blood pressure, heart rate and the amount of bleeding based on the number of consumed pads, fever, chills, diarrhea and vomiting were checked and recorded.

If placental expulsion did not occur in an hour or the vital signs of mother were unstable, or vaginal bleeding was severe, the patients would undergo curettage and the uterine contents would be removed and sent to pathology. In case 
of placental delivery during 1 hour, the patient underwent ultrasonography to be examined for remains of pregnancy. The time of fetal delivery, the time between fetal delivery and placental expulsion, and the amount of mother's bleeding were recorded based on reduction of hemoglobin (before abortion and 24 hours after the abortion). The exclusion criteria in this study were having allergy or intolerance to misoprostol, hypertension over $90 / 160 \mathrm{~mm} \mathrm{Hg}$, having severe cardiovascular disease, very bad patient's general condition, history of previous uterine scar (except for having one transverse cesarean incision in the lower segment of uterine layer), presence of medical abortion contraindications like severe anemia, using anticoagulants or having coagulation disorders, active liver disease, uncontrolled seizure disorders, adrenal disease (Addison), disorders requiring treatment with corticosteroids and fetal removal via non-medical methods.

\section{Statistical Analysis}

Collected data were entered into SPSS version 20 and analyzed using descriptive and analytical statistical methods such as chi-square test and test for comparing the variables between the two groups. In all tests, the significance level was set at less than 0.05 .

\section{Results}

In this study, the groups were not significantly different from each other in terms of demographic and medical information such as age, gestational age, hemoglobin levels at admission and other details related to the number of pregnancy (Table 1). As Table 2 displays, the frequency of retained placenta in the misoprostol group with 4 patients (8\%) was less than the oxytocin group with 8 cases $(16 \%)$, but not statistically significant. Most cases of retained placenta in the oxytocin group and the misoprostol group relates to gestational age less than 16 weeks with 4 patients (50\%) and 3 cases (75\%), respectively. Average time for placental expulsion was $19.8 \pm 12$ minutes in the oxytocin group and 21.4 \pm 9.2 minutes in the misoprostol group and there was no statistically significant difference between the two groups. Comparing the remnants of pregnancy after the expulsion of the placenta via sonography revealed a significant difference between the two groups, i.e., 15 cases $(30 \%)$ in the misoprostol group and 30 cases (60\%) in the oxytocin group.

Also, in cases with positive reports of ultrasound ( 15 cases [30\%] in the misoprostol group and 29 cases [58\%] in the oxytocin group), the presence of placenta confirmed by pathology was significantly different between two groups

Table 1. Demographic Information of Two Groups Before Study

\begin{tabular}{lccc}
\hline Variables & Misoprostol & Oxytocin & $\boldsymbol{P}$ \\
\hline Mean age of mothers (year) & $26.1 \pm 4.5$ & $27.2 \pm 5.9$ & 0.12 \\
$\mathrm{Hb}$ & $11.5 \pm 1.2$ & $11.8 \pm 1.2$ & 0.3 \\
Gestational age & $18.6 \pm 3.7$ & $18.2 \pm 3.6$ & 0.57 \\
Placental expulsion time (min) & $21.4 \pm 9.2$ & $19.8 \pm 12$ & 0.45 \\
\hline
\end{tabular}

$(P=0.032)$. Serum hemoglobin level represented a significant reduction in both groups after abortion. The amount of reduction in the oxytocin group with 0.8 units was significantly higher than the misoprostol group with 0.54 units $(P=0.001)$. The number of cases who underwent emergent curettage was $4(8 \%)$, that occurred in the oxytocin group due to excessive bleeding and changes in the mother's vital signs, but no emergent curettage was seen in the misoprostol group. No drug side effects were seen in both groups with administered doses. The amount of bleeding based on the number of used pads did not differ significantly in the two groups.

\section{Discussion}

Retained placenta is one of the most significant complications in the result of abortions, which requires surgical intervention for removal. Some studies have reported the frequency of retained placenta after terminating pregnancy with prostaglandins about $80 \%$ (8). Despite surgical intervention seems safer in termination of pregnancy, in cases in which abortion is induced because of fetal anomalies, it is accompanied by surgery risks and requires the surgeon's dexterity (9).

Different studies, considering the experts' suggestions, have used various protocols like intramuscular syntometrin (10), intravenous oxytocin (11), intramuscular PGF2 $\alpha$ (12) and in some cases expected intervention and routine curettage have been recommended $(10,13)$. To reduce the postpartum bleeding after delivery and to have less intervention in the third stage of labor, it is better to have active interventions in placental expulsion. In this study, the selected intervention was of the type that can be used in most of clinical cases.

Regarding the results of the present study, the duration of the placental expulsion in the rectal misoprostol group and intravenous oxytocin group was similar. The frequency of cases with retained placenta in the misoprostol group with $4(8 \%)$ was lower than the oxytocin group with $8(16 \%)$, but this difference was not statistically significant. It is worth mentioning that the cost of misoprostol is less than oxytocin.

Although the level of hemoglobin was decreased in both groups, greater decrease was seen in the oxytocin group. Misoprostol has several comparative advantages. There are some studies that have shown the effectiveness of misoprostol compared with oxytocin in inducing abortion

Table 2. Comparison of Variables Between Two Groups

\begin{tabular}{lccc}
\hline Variables & $\begin{array}{c}\text { Misoprostol, } \\
\text { No. (\%) }\end{array}$ & $\begin{array}{c}\text { Oxytocin, No. } \\
\text { (\%) }\end{array}$ & $\boldsymbol{P}$ \\
\hline $\begin{array}{l}\text { Retained placenta } \\
\text { Remains of pregnancy after }\end{array}$ & $4(8)$ & $8(16)$ & 0.21 \\
$\begin{array}{l}\text { ultrasound } \\
\text { Emergent curettage }\end{array}$ & $0(0)$ & $30(60)$ & 0.003 \\
$\begin{array}{l}\text { Bleeding } \\
\text { Excessive }\end{array}$ & $15(8)$ & 0.039 \\
$\quad$ Moderate & $1(2)$ & $1(2)$ & 0.37 \\
$\quad$ Heavy & $27(54)$ & $20(40)$ & \\
\hline
\end{tabular}


and have reported lower percentage of retained placenta ( $2 \%$ vs. $15 \%$ ) (14). The same pattern was observed in the present study ( $8 \%$ vs. $16 \%$ ), and the slight difference between the results can be attributed to the larger sample size and to selecting population according to different criteria in other studies. In general, conducted studies have reported lower level of retained placenta in patients that had used misoprostol for abortion (10).

The present study revealed the superiority of rectal misoprostol regimen over intravenous oxytocin. Previously, other studies had shown similar results for oral misoprostol (15).

Contrary to our findings, some studies have reported that the percentage of retained placenta and the amount of bleeding in the intervention group of oxytocin were significantly lower in the intramuscular oxytocin group (10). However, due to the easy use of misoprostol and its lower price and stability at room temperature, it seems reasonable to be employed in the interventions of the third stage of labor. The controversy among study' results is likely to be because of various methods used for inducing abortions, different doses and methods and finally diverse inclusion and exclusion criteria in different hospitals. While in the studies of Parsons et al and Mansouri et al, no difference was found between the effectiveness of rectal misoprostol and intravenous oxytocin, they suggested administering it, particularly in the less developed countries, because of the above mentioned reasons. Additionally, in a clinical trial that compared the effectiveness of rectal misoprostol with oxytocin accompanied by methyl ergometrin, the latter showed better results $(16,17)$.

Some studies have shown that acceptable time for placental expulsion in the third stage of labor can last up to six hours $(8,9)$. In this study, in both groups, on average, placental expulsion occurred in less than one hour. This shows the positive effect of intervention in the third stage of labor which can significantly decrease its complications through considerable reduction in the duration of placental removal. It seems that in case of complications, interventional approach should be preferred to expected approach. Although in respect of the pharmacokinetics, misoprostol can be absorbed via different ways (rectally or vaginally), but their similar final effect is confirmed (18). In the present study, $400 \mu \mathrm{g}$ rectal misoprostol regime was used, which was found clinically effective. A clinical trial in 2003, showed the efficacy of rectal misoprostol and its lower bleeding and complications as compared to other regimes (19).

It was also reported that $800 \mu \mathrm{g}$ of rectal misoprostol can reduce bleeding during cesarean in comparison with intravenous oxytocin which was similar to the findings of this study.

\section{Conclusion}

Results showed that the use of rectal misoprostol in the third stage of abortion in the second trimester of pregnancy can be effective as compared to intravenous oxytocin, in reducing the amount of bleeding and retained products of conception and placenta and the number of cases requiring emergent curettage.

\section{Ethical Issues}

The study protocol was registered in Iranian Registry of Clinical Trials (IRCT) (IRCTID: IRCT2015020715795N2) and confirmed by ethical committee of Ardabil University of Medical Science.

\section{Conflict of Interests}

The authors declare no conflict of interests.

\section{Finnacial Support}

The researchers received no financial support or grant from any funding agency in the public and commercial sectors.

\section{Acknowledgments}

The authors are grateful to Ardabil University of Medical Science for supporting this work as a source of funding.

\section{References}

1. Guzeloglu-Kayisli O, Kayisli UA, Taylor HS. The role of growth factors and cytokines during implantation: endocrine and paracrine interactions. Semin Reprod Med. 2009;27(1):62-79. doi: 10.1055/s-0028-1108011.

2. Clark K, Ji H, Feltovich H, Janowski J, Carroll C, Chien EK. Mifepristone-induced cervical ripening: structural, biomechanical, and molecular events. Am J Obstet Gynecol. 2006;194(5):1391. doi: 10.1016/j. ajog.2005.11.026.

3. Karjane NW, Brock EL, Walsh SW. Induction of labor using a foley balloon, with and without extraamniotic saline infusion. Obstet Gynecol. 2006;107(2 Pt 1):234-9.

4. Cunningham FG, Leveno KJ, Bloom SL, et al. Williams Obstetrics. 23rd ed. New York: McGrawHill; 2010. p. 230-240.

5. Karsidag A, Buyukbayrak EE, Kars B, Dansuk R, Unal O, Turan MC. Vaginal versus sublingual misoprostol for second trimester pregnancy termination and effect on Doppler measurements. Int J Gynaecol Obstet. 2009;106(3):250-3. doi: 10.1016/j.ijgo.2009.04.001.

6. Bhattacharjee N, Saha SP, Ghoshroy SC, Bhowmik S, Barui G. A randomised comparative study on sublingual versus vaginal administration of misoprostol for termination of pregnancy between 13 to 20 weeks. Aust N Z J Obstet Gynaecol. 2008;48(2):165-71. doi: 10.1111/j.1479828X.2008.00831.x.

7. Hofmeyr GJ, Gülmezoglu AM, Novikova N, Linder V, Ferreira S, Piaggio G. Misoprostol to prevent and treat postpartum haemorrhage: a systematic review and meta-analysis of maternal deaths and dose-related effects. Bull World Health Organ. 2009;87(9):666-77.

8. Chaudhuri P, Banerjee GB, Mandal A. Rectally administered misoprostol versus intravenous oxytocin infusion during cesarean delivery to reduce 
intraoperative and postoperative blood loss. Int J Gynaecol Obstet. 2010;109(1):25-9. doi: 10.1016/j. ijgo.2009.11.009.

9. Lohr PA, Hayes JL, Gemzell-Danielsson K. Surgical versus medical methods for second trimester induced abortion. Cochrane Database Syst Rev. 2008;1:CD006714. doi: 10.1002/14651858.CD006714. pub2.

10. Dickinson JE, Doherty DA. Optimization of third-stage management after second-trimester medical pregnancy termination. Am J Obstet Gynecol. 2009;201(3):303.e1-7. doi: 10.1016/j. ajog.2009.05.044.

11. Green J, Borgatta L, Sia M, Kapp N, Saia K, Carr-Ellis $\mathrm{S}$, Vragovic O. Intervention rates for placental removal following induction abortion with misoprostol. Contraception. 2007;76(4):310-3. doi: 10.1016/j. contraception.2007.06.010.

12. Sundaram S, Diaz JP, González-Quintero VH, Verma U. Rectal misoprostol vs 15-methyl prostaglandin F2alpha for retained placenta after second-trimester delivery. Am J Obstet Gynecol. 2009;200(5):e24-6. doi: 10.1016/j.ajog.2008.09.868.

13. Carbonell JL, Torres MA, Reyes R, Ortega L, GarcíaGallego F, Sánchez C. Second-trimester pregnancy termination with 600 microg vs. 400-microg vaginal misoprostol and systematic curettage postexpulsion: a randomized trial. Contraception 2008;77(1):50-5. doi: 10.1016/j.contraception.2007.09.007.

14. Aziz S, Kazi S, Haq G, Soomro N. Oral misoprostol versus oxytocin in the management of third stage of labour. J Pak Med Assoc. 2014;64(4):428-32.

15. Prata N, Hamza S, Gypson R, Nada K, Vahidnia F, Potts M. Misoprostol and active management of the third stage of labor. Int J Gynaecol Obstet. 2006;94(2):149-55.

16. Parsons SM, Walley RL, Crane JM, Matthews K, Hutchens D. Rectal misoprostol versus oxytocin in the management of the third stage of labour. J Obstet Gynaecol Can. 2007;29(9):711-8.

17. Mansouri HA, Alsahly N. Rectal versus oral misoprostol for active management of third stage of labor: a randomized controlled trial. Arch Gynecol Obstet. 2011;283(5):935-9. doi: 10.1007/s00404-0101466-5.

18. Leader J, Bujnovsky M, Carlan SJ, Triana T, Richichi K. Effect oforal misoprostol after second-trimester delivery: a randomized,blinded study. Obstet Gynecol. 2002;100(4):689-94.

19. Svanström MC, Biber B, Hanes M, Johansson G, Näslund U, Bålfors EM. Signs of myocardial ischaemia after injection of oxytocin: a randomized double - blind comparsion of oxytocin and methylergometrine during caesarean section. $\mathrm{Br} \mathrm{J}$ Anaesth. 2008;100(5):683-9. doi: 10.1093/bja/aen071.

Copyright () 2016 The Author(s); This is an open-access article distributed under the terms of the Creative Commons Attribution License (http://creativecommons.org/licenses/by/4.0), which permits unrestricted use, distribution, and reproduction in any medium, provided the original work is properly cited. 